\title{
Mobile Money: The Effect of Service Quality and Competition on Demand
}

\section{Citation}

Balasubramanian, Karthik, and David F. Drake. "Mobile Money: The Effect of Service Quality and Competition on Demand." Harvard Business School Working Paper, No. 15-059, January 2015.

\section{Permanent link}

http://nrs.harvard.edu/urn-3:HUL.InstRepos:13851737

\section{Terms of Use}

This article was downloaded from Harvard University's DASH repository, and is made available under the terms and conditions applicable to Open Access Policy Articles, as set forth at http:// nrs.harvard.edu/urn-3:HUL.InstRepos:dash.current.terms-of-use\#OAP

\section{Share Your Story}

The Harvard community has made this article openly available.

Please share how this access benefits you. Submit a story.

\section{Accessibility}


H A R VAR D

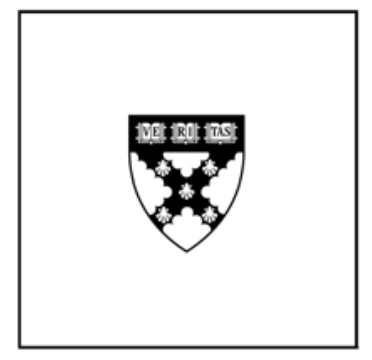

\section{Mobile Money: The Effect of Service Quality and Competition on Demand}

Karthik Balasubramanian David F. Drake

\section{Working Paper}

15-059

January 13, 2015 


\title{
Submitted to Manufacturing $\mathcal{G}$ Service Operations Management
}

\section{Mobile Money: The Effect of Service Quality and Competition on Demand}

\author{
Karthik Balasubramanian and David F. Drake \\ Harvard Business School, Harvard University, Boston, MA 02163 \\ Corresponding author: kbalasubramanian@hbs.edu
}

The use of electronic money transfer through cellular networks ("mobile money") is rapidly increasing in the developing world. The resulting electronic currency ecosystem could improve the lives of the estimated 2 billion people who live on less than $\$ 2$ a day by facilitating more secure, accessible, and reliable ways to store and transfer money than are currently available. The development of this ecosystem requires a network of agents to conduct cash-for-electronic value transactions and vice versa. This paper estimates the effect of competition and service quality on mobile money demand. In this setting, service quality consists of service reliability (lower stockout and system downtime rates), pricing transparency, and agent expertise. Among our results, we find that agents experience reduced demand for service failures due to stockouts, but not for service failures due to network downtime, suggesting that consumers differentially ascribe responsibility for service failure based on the type of failure they experience. We find that both stockout rate and agent expertise are important competitive dimensions in this setting. Pricing transparency, on the other hand, has a main effect on demand but has no significant interaction with competitive intensity. This paper furthers our understanding of the impact and interaction of quality and competition in service settings, while developing a foundation for the exploration of mobile money by OM scholars.

Key words: service operations, operations strategy, competition, base of the pyramid, mobile money

\section{Introduction}

In the past 7 years, "mobile money" platforms have experienced explosive growth in the developing world, now with 219 active mobile money systems in 84 countries (Groupe Speciale Mobile Association 2013). These platforms, primarily built and managed by mobile network operators, allow money to be stored in the form of digital currency (hereafter referred to as e-float). In much the same way that text messages can be sent quickly and cheaply, e-float can be securely and instantly transferred across long distances at a near-zero marginal transaction cost. Mobile money platforms are of particular interest to the base of the pyramid $(\mathrm{BoP})$ community - scholars and practitioners developing business models deliberately geared toward serving the population in poverty-because they have potential to connect millions of poor and "unbanked" people to the formal financial system. This has potential to provide several benefits: i) it can enable quicker recovery from economic shocks such as job loss or illness to the primary wage-earner (Jack and Suri 2014); ii) it can 
enable more efficient receipt of monetary transfers from non-governmental organizations (NGOs) after disasters (Aker et al. 2011); and iii) it can lay the foundation for access to formal savings, credit, and insurance opportunities to those who currently lack such access (Mas 2010).

A highly reliable network of cash-in/cash-out (CICO) agents to serve as the bridge between physical cash and e-float is critical to the success of mobile money platforms. These agents, often small shop-owners, convert cash to e-float ("cash-in" transactions) and e-float back to cash ("cashout" transactions) for a commission. Because these agents ensure the convenient convertibility of e-float, the reliability with which they perform such transactions is crucial to consumer confidence in the platforms. However, due to stockouts of cash or e-float, agents are often unable to satisfy consumer demand for CICO services-i.e., an agent's fundamental challenge in managing their CICO business is an inventory problem. Consequently, operations management scholars have a role to play in the development of robust mobile money ecosystems.

The contract and inventory theory tools developed over the past decades can apply to this fundamentally new context, but as community, we must first develop an understanding of the mobile money business, particularly the nature of demand. Accordingly, we seek to provide an introduction to mobile money and explore the effects of competition and service quality on that demand. Specifically, we explore two overarching questions: what is the main effect of an agent's service quality on their steady-state demand, and what is the effect of competitive intensity? With respect to the first question, we are interested in three dimensions of service quality pertinent in this context: i) service reliability (i.e., lower stockout and system downtime rates); ii) pricing transparency (related to agent credibility); and iii) agent expertise (related to agent competence). With respect to the second question, we are interested in both the main effect of competitive intensity and in understanding how competitive intensity moderates the effect of these dimensions of service quality on demand.

To answer these questions, we use a combination of agent network and demographic data sources from Kenya and Uganda, two East African countries at different stages of mobile money market development. We utilize an in-person survey of over 4,400 mobile money agents that operate in the two countries. We then combine the locations of the surveyed agents with the precise locations of over 68,000 bank branches, bus stands, and mobile money agents, as well as population and poverty estimates for each square kilometer of the countries. We find that an agent's reduction in steady-state demand for stocking out of cash or e-float is economically and statistically significant. However, agents do not experience decreased demand when they are unable to fulfill demand due to a system outage. Mobile money consumers, therefore, appear to differentially ascribe transaction failure ownership, and agents are affected accordingly. Agents who are more transparent with transaction pricing and agents who are more knowledgeable experience relatively greater 
Balasubramanian and Drake: Service Quality, Competition, and Mobile Money Agent Demand

Article submitted to Manufacturing $\&$ Service Operations Management

demand. Agents' pricing transparency does not interact with competitive intensity. Agents that provide more reliable and more knowledgeable service, on the other hand, reap greater rewards from their performance in the face of greater competition. This can be related to Hill's (1993) operations strategy framework of "order-qualifiers" and "order-winners": pricing transparency acts as an "order-qualifier" among a portion of the consumer-base, while reliability and expertise are "order-winners" as dimensions along which agents compete.

\section{Literature review}

Our work relates to literature focused on inventory service level, service quality, competition, and operations at the base of the pyramid (BoP).

In inventory management, there are two broad classes of mismatch costs: i) holding and spoilage costs incurred by carrying too much inventory; and ii) stockout costs, which are opportunity costs incurred by carrying too little inventory. With our focus on steady-state demand effects, we are interested in the latter. There are two primary components to stockout cost: the immediate cost and the future cost. In its basic form, the immediate cost is relatively simple to calculate: it can be computed directly as the difference between the margin of the out-of-stock good and the expected value of the recoverable margin (which is the product of margin, the likelihood of the customer returning for the same good, and any applicable discount factor). Using survey data from Ohio liquor store customers, Walter and Grabner (1975) measure this immediate cost, and also account for substituting the stocked-out product for a similar product of a different brand or size. The loss of future demand due to stockouts can be more difficult to estimate. Schwartz (1966) coined the term "perturbed demand" in his seminal work modeling the loss of consumer goodwill that a firm experiences in the aftermath of a stockout. "Perturbed demand" refers to the decrease in future demand, where this decrease is a function of the magnitude of the stockout. Anderson et al. (2006) empirically estimate the short and long-run costs of stockouts for a mail order catalog, finding these costs to be both statistically and economically significant. However, Anderson et al. (2006) do not account for competition among firms, nor do they account for geographic variation in the firm's customer base (such as population density and socio-economic status) as we do. Using a branded apparel context, Craig et al. (2014) study supplier- retailer relationships. They find that higher supplier service levels have a large effect on suppliers' demand from retailers when supplier service levels are already high: a $1 \%$ increase in historical supplier service level is associated with a $13 \%$ increase in demand from retailers.

Service quality has attracted interest in the past three decades. While quality has a plethora of definitions (Reeves and Bednar 1994), we focus on three widely-recognized dimensions of service quality: reliability, credibility, and competence (Parasuraman and Zeithaml 1988). In the mobile 
money context, reliability (service failure) is measured through stockout and system downtime rates. We measure credibility and competence, respectively, through each agent's pricing transparency and their expertise with respect to transaction policies and procedures. With respect to service failures, Taylor (1994) studies the attribution of blame for service failures in the context of airline delays and finds that attribution is associated with the perception of firm control over the delay (e.g. travelers are less likely to blame an airline for delays due to inclement weather than for mechanical failures). Taylor (1994) studies attribution of blame with an attitudinal questionnaire, while we study a more tangible quantity of interest: demand impacts.

While (to the best of our knowledge) there are no empirical studies that directly explore the effect of pricing transparency and a provider's expertise on demand, the framework of trust developed in the literature is relevant. A generally accepted conceptualization of trust is two-dimensional: trust is composed of "benevolence trust" and "competence trust" (Singh and Sirdeshmukh 2000). Benevolence trust (the faith customers have in firms not to cheat them) is related to our measure of credibility (i.e., pricing transparency) and competence trust (the faith customers have in firms to be able to competently fulfill demand) is related to agent expertise. Both of these concepts and their applications are discussed further in Section 4 where we develop our hypotheses.

In addition to literature exploring inventory management and service quality, there has also been interest in the effect of competition on inventory decisions and service quality. Olivares and Cachon (2009) argue that the theory on this question is mixed. On one hand, higher competition will drive down price, predicting a lower optimal inventory service level. On the other hand, higher competition will force firms to compete on service level, driving service level up. In the context of the US auto market, Olivares and Cachon (2009) find that greater competition among dealers results in higher service levels. Allon et al. (2011) develop a structural estimation model to quantify the impact of wait time (as opposed to inventory stockout rate, pricing transparency, and transaction expertise) on consumer demand in the US fast-food industry. Our work differs markedly from these contributions. First, the context is vastly different-rather than estimating the impact of service level in the US auto or fast-food sector, we focus on a financial service in the developing world. Secondly, because we have estimates of sales from agents, we do not need to impute them through the use of a structural model, as Allon et al. (2011) do. Thirdly, to the best of our knowledge, we are the first to empirically study how the reduction in demand related to stockouts varies with the level of competitive intensity that firms (agents, in our context) face.

Finally, because mobile money has potential to dramatically lower the cost structure of serving the poor with financial services, mobile money is fundamentally related to the emerging literature on serving the BoP (Prahalad and Hammond 2002). Research in the operations management community focused on BoP is quite nascent (e.g., Sodhi and Tang 2011; Gold et al. 2013). Our work here contributes to this emerging stream. 
Balasubramanian and Drake: Service Quality, Competition, and Mobile Money Agent Demand

Article submitted to Manufacturing \& Service Operations Management

\section{Context}

In this section, we provide an overview of mobile money's history, impact, and implications. We also describe the mechanics of a mobile money transaction, as well as challenges and opportunities confronting mobile money systems.

\subsection{Mobile money motivation and history}

The poor comprise the vast majority of the "unbanked", the nearly 2.5 billion people globally who do not have an account at a formal financial institution (Demirguc-kunt and Klapper 2012). The poor and unbanked-roughly one-third of the world's population-rely mostly on physical cash when transferring money. Thus, the velocity of money is limited by how fast cash can be physically transported, by foot or by bus in most circumstances (Batista and Vicente 2013). This limitation is a critical disadvantage to the poor when money is needed most, such as in the aftermath of a negative economic shock (e.g., sickness or job loss) or a rare opportunity to climb out of poverty through investment (e.g., fertilizer or improved seed purchases) (Helms 2006). At these decisive moments, friends and family willing and able to transfer money must rely on expensive and/or unreliable methods such as bus money transfer services (Morawczynski 2009). Furthermore, saving for these pivotal moments is more challenging with inferior savings tools: to store and save money, most either hide cash in their homes (at risk of theft and ineligible for interest), or purchase relatively illiquid assets like gold or livestock (that are often sold at a loss in times of need) (Collins et al. 2009). One study found that among a large sample of the poor in Uganda, $75 \%$ had lost some portion of their cash or physical asset savings in the previous year (Wright and Mutesasira 2001). Similarly, informal credit for investment opportunities and insurance options for risk mitigation are substandard among the unbanked; credit is often only available from moneylenders at usurious rates, and formal insurance is generally inaccessible, if it exists at all (Collins et al. 2009). The poor, especially those living in rural areas, remain unserved by formal financial institutions because their low balances and transaction sizes yield little revenue for banks (Mas 2010). Furthermore, because the rural poor live in definitionally low density and remote areas, these regions lack the scale to make the provision of traditional financial services an attractive proposition. Consequently, financial institutions have largely found it impractical to profitably serve the poor in the developing world (Kendall 2011).

The rapid growth of cellular networks in the developing world in the past decade lays the groundwork for a potential paradigm shift in financial services for the poor. According to the Boston Consulting Group (BCG), the number of unbanked in the developing world with access to mobile phones was estimated to be 2 billion in 2011, and that number is likely to continue to grow (BCG 2011). Recognizing this opportunity in 2003, the UK Department for International Development 
approached Vodafone and its Kenyan affiliate, Safaricom, about developing and piloting a new service in Kenya that would allow micro-credit institutions to disburse loans and receive repayments electronically. After the pilot project, Safaricom noticed that many people were using the service to repay the loans of others (generally as a means of settling a secondary transactional obligation). Safaricom quickly realized the potential of its service as a tool for domestic money transfer. They branded the product "M-Pesa" ("Pesa" means "money" in Swahili) and launched the service in March of 2007 (Buku and Meredith 2013). The uptake was rapid - in less than five years, M-Pesa amassed over 12 million customers from among Kenya's population of 45 million (Figure 1 depicts M-Pesa's growth). Several years later, neighboring Uganda also experienced rapid growth in mobile money adoption.

M-Pesa continues to dominate the mobile money market in Kenya, with nearly $70 \%$ market share as of 2013. Its closest competitor is Airtel Kenya, with less than $20 \%$ market share. The industry is even more consolidated in Uganda, where MTN Uganda has over $80 \%$ of the active mobile money accounts in the country, while its closest competitor, Airtel Uganda, has only $10 \%$ of the country's active mobile money accounts (Intermedia 2013). Due to each country's central bank regulations restricting international remittances, mobile money operators in East Africa are limited to serving customers in a single country.

\section{Growth of M-Pesa in Kenya}

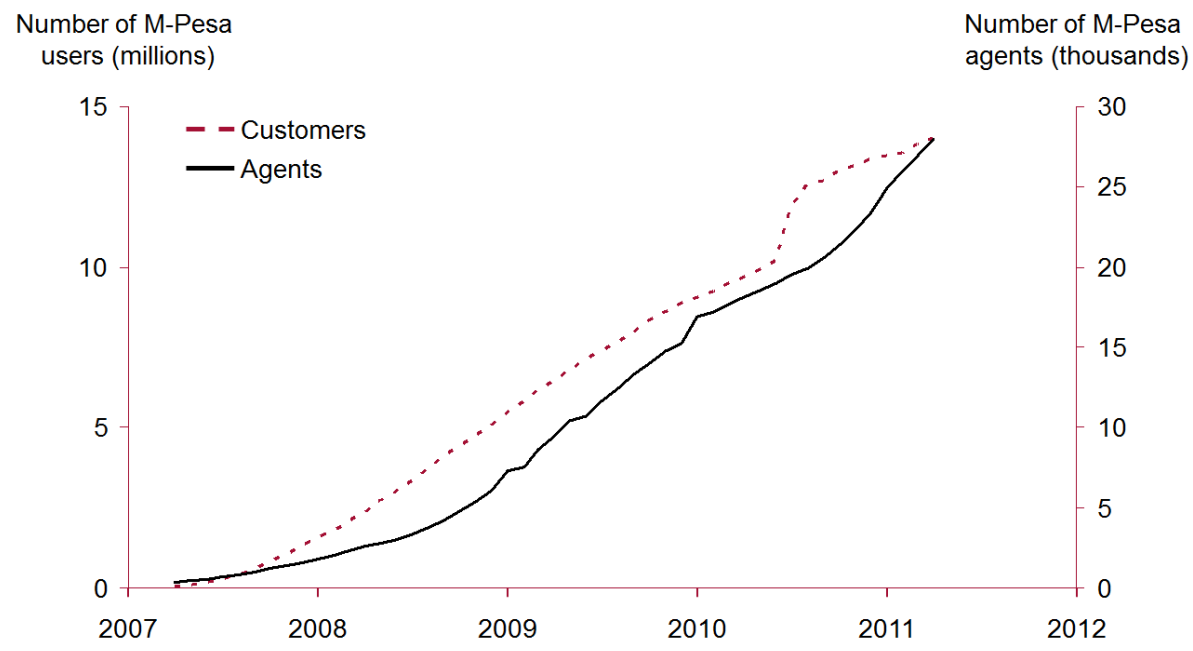

Figure 1 Growth of M-Pesa customers and agents in Kenya, adapted from Jack and Suri (2014)

\subsection{Transaction mechanics and inventory challenges}

As M-Pesa's tagline, "send money home", would suggest, the use of mobile money to remit money to a family member or friend from an urban area to a rural area grew quickly. The following is 
a very typical use case: An urban laborer in Nairobi, Kenya gets paid in cash. He conducts a cash-in transaction with an urban agent in which he gives the agent cash and the agent credits the laborer's mobile money account with e-float (Stage 1 in Figure 2). For her role in executing the transaction, the agent receives a cash-in commission from the mobile money operator (e.g., Safaricom). (Notably, customers do not pay for cash-in transactions in any currently active mobile money network.) The laborer, now with a balance of mobile money, sends this e-float to his family outside of Kisumu, Kenya with his phone (not necessarily a smartphone), in much the same way he might send an SMS message (Stage 2 in Figure 2). The operator collects a fee from the laborer for executing this person-to-person (P2P) transfer. Having instantaneously received the e-float onto her phone, the laborer's wife goes to the local agent outside of Kisumu to conduct a cash-out transaction. She gives the agent e-float in exchange for cash (Stage 3 in Figure 2), paying the mobile money operator a cash-out fee. Like the cash-in agent, the cash-out agent is also compensated with a commission from the operator for her role in executing the transaction. ${ }^{1}$

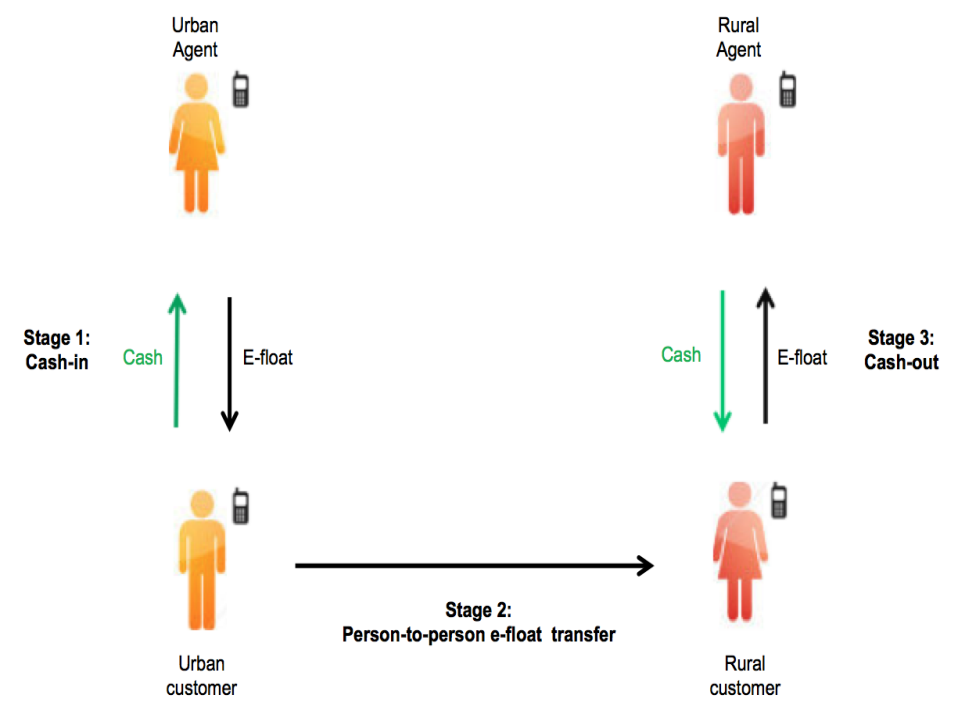

Figure 2 Schematic of a typical urban-to-rural person-to-person transfer, adapted from Agrawal (2009)

In order to conduct a cash-in or cash-out transaction, the agent must have inventory of e-float or cash, respectively. Unfortunately, stockouts are an acute problem in mobile money networks. In rural areas, agents often run out of cash. Our data show that even in urban settings, service levels can fall well below $80 \%$ for cash-out transactions. Agents also run out of e-float, but to a lesser

\footnotetext{
${ }^{1}$ Cash-out commissions are generally larger than cash-in commissions, typically by $50 \%$ or more. These commissions are generally determined as an increasing step function of transaction value.
} 
degree (Intermedia 2013). Because stockouts of cash and e-float make it harder for customers to easily convert between the two forms of money, they degrade consumer confidence in the convenient convertibility of e-float.

When an agent stocks out of cash, the customer desiring to cash-out has two options: she can return to the same agent later with the hope that the agent has replenished his inventory of cash; or, she can travel to a different agent within the same operator network to cash-out (assuming that this second agent has cash available). When the customer desiring to cash-in experiences a stockout of e-float, the customer has the above two options, as well as a third option: to travel to an agent serving a different operator, assuming that the person he is sending money to also has an account with the competing operator. Note that because e-float is actual currency, it cannot be "created" on the spot by either the agent or the operator. Each unit of e-float an operator issues must be backed by traditional deposits at a prudentially regulated financial institution. Though moving e-float once it has been issued is clearly easier than moving cash, agents can still stock out of e-float if they have not been able to procure enough e-float to satisfy demand.

\section{Hypothesis development}

Here we develop hypotheses related to service quality - in terms of service reliability, pricing transparency, and expertise - and competitive intensity, including its interaction with service quality.

\subsection{Service reliability}

We measure service reliability by its inverse: service failure. There are two possible sources of CICO agent service failure - the agent may be out of inventory, or the system may be down. Under either form of service failure, the customer arrives to the agent, requests the transaction, and then receives news that their transaction cannot be completed. Although the end result is the same under both forms of service failure, we posit that the effect of these failures on agents differ by failure type.

The effect of stockouts on demand has been researched in other contexts. Schwartz (1966) theorizes in his perturbed demand model that customers will decrease their patronage of firms that disappoint them by stocking out of desired products. Anderson et al. (2006) show that customers who experienced stockouts do indeed purchase less in the future. We expect to see an analogous "stockout effect" in the mobile money context; stockouts of cash and e-float likely result in a reduction of steady-state demand for CICO transactions.

Just as stockouts effectively deny customers the ability to carry out their desired transaction with an agent, so too will system failure. On an agent level, do customers react differently to system failures than they do for stockouts even though the outcome, a denied transaction, is fundamentally the same? Anderson et al. (2006) find that there is no meaningful difference in future customer purchasing behavior between customers experiencing a stockout who were told "this item is out of 
Balasubramanian and Drake: Service Quality, Competition, and Mobile Money Agent Demand

stock" versus customers experiencing a stockout who were informed "this item is out of stock due to a problem with a supplier." Therefore, the findings of Anderson et al. (2006) imply that customers might reduce their patronage of agents in response to supplier failures, which in this case would be operator failures. However, in the mobile money context, an agent can demonstrate to customers that the system is down by showing the system error message on her phone to the customer; this effectively absolves the agent of blame for the denied transaction. Even though stockouts may also be out of the agent's control (e.g., there may be systemic cash or e-float shortages), the customer cannot with certainty absolve agents of blame for stocking out. In an airline setting, Taylor (1994) shows that consumer attribution of blame is associated with the degree to which consumers perceive the firm is in control of the service failure. Therefore, we posit that consumers will be less likely to attribute blame to the agent for system failures than for stockouts. We therefore expect the reduction of demand associated with system failures, which we term the "system-down effect", to be less severe than the loss of demand associated with stockouts.

Hypothesis 1. A) The higher the fraction of total demand that is unmet due to agent stockouts, the lower the agent's steady-state demand. B) The reduction in demand associated with system failures is less severe than for stockouts.

\subsection{Pricing transparency and agent expertise}

We posit that agent pricing transparency and agent expertise, two additional factors of service quality, are also important influencers of demand. In this case, both of these quality elements can be examined through a customer trust lens. As we mention previously, a generally accepted conceptualization of trust is two-dimensional: trust is composed of "benevolence trust" and "competence trust" (Singh and Sirdeshmukh 2000).

Benevolence trust is commonly defined as the "perceived willingness of the trustee to behave in a way that benefits the interests of both parties, with a genuine concern for the partner, even at the expense of profit" (Garbarino and Lee 2003). Posting of CICO pricing is both mandated by operators and expected by consumers. The absence of pricing transparency may serve as a warning sign to customers and therefore may degrade benevolence trust. This relates to emerging "disclosure" literature. The key difference is that, in the disclosure literature, the established norm is non-transparency - organizations have the decision whether or not to reveal traditionally unobservable information such as their environmental performance (e.g., Toffel and Reid 2009; Kalkanci and Plambeck 2012), corporate social responsibility (e.g., Dhaliwal et al. 2011; Gamerschlag et al. 2010), or operational processes (e.g., Buell and Norton 2011). In our setting, however, the established norm with respect to pricing is one of transparency - operators mandate that the 
tariff be posted, and the majority (92\%) of agents comply with this mandate. We posit that violating the established transparency norm erodes benevolence trust and that non-compliance (i.e., non-transparency) will therefore attenuate demand.

The second component of trust, competence trust, is generally defined as the perceived ability of the firm to deliver services reliably and without flaws (Garbarino and Lee 2003). A customer has competence trust in an agent if the customer believes that the agent has the knowledge and ability to properly conduct CICO transactions (e.g., the agent knows the correct daily transaction limits, identification requirements, and other operator policies regarding the use of mobile money). Though expertise cannot be observed as easily as pricing transparency (presence of a posted tariff sheet), agent expertise (or lack thereof) can be assessed by customers if guidance from agents is either confirmed or discovered to be incorrect. Perceptions of expertise can also be shaped by the opinions and experiences of those in the customer's social network. Greater expertise would thus naturally lead to greater competence trust.

Sun and Lin (2010) find that department store benevolence trust and competence trust both increase customer loyalty (measured on a scale that includes future repeat purchase intent). Because transparency likely engenders benevolence trust in agents, and expertise likely engenders competence trust in agents, we posit the presence of a "transparency effect" and an "expertise effect": customers reward agents for pricing transparency and expertise, respectively, with higher demand.

Hypothesis 2. A) Customers reward agents for pricing transparency; steady-state demand increases with pricing transparency. B) Customers reward agents for expertise; steady-state demand increases with agent expertise.

\subsection{Competition}

Intuition suggests that in most settings competitive intensity would attenuate demand, as consumers have a choice between a firm and its competitor(s). Indeed, in their study of auto dealerships, Olivares and Cachon (2009) label this the "sales effect": increased competition decreases a dealer's sales. We posit that this effect is present in the mobile money context as well: increasing competitive intensity (increasing the number of proximate competitors) decreases each agent's steady-state demand.

Furthermore, with product differentiation and price (standardized by operators) off the table as competitive dimensions, we posit that service quality provides a primary basis for competitive differentiation among agents. Specifically, we hypothesize that the interaction of stockouts with competitive intensity is negative; i.e., reduction in demand associated with stockouts is more severe when competitive intensity is greater. Given proximate alternatives to an agent who stocks out 
Balasubramanian and Drake: Service Quality, Competition, and Mobile Money Agent Demand

often, customers will likely exercise the option to use these alternatives. This relates to an observation by Olivares and Cachon (2009), who notice that service level increases with competition and speculate that this is because retailers intuit that customers will be able to defect relatively easily in response to low service levels-customers can simply go to a proximate competitor offering an identical product.

Analogously, we posit that agents who engender benevolence trust by being more transparent will be able to attract demand away from agents who do not engender such trust. We therefore hypothesize that the interaction between competitive intensity and pricing transparency is positive (i.e., the rewards for transparency increase with competitive intensity).

Similarly, we posit that agents who engender greater competence trust by demonstrating expertise will be able to attract demand away from agents who do not. As with pricing transparency, we hypothesize that the interaction between competitive intensity and expertise is positive (i.e., the rewards for expertise increase with competitive intensity).

Hypothesis 3. A) Agent demand decreases in competitive intensity. B) Competitive intensity exacerbates the reduction in demand related to stockouts. C) Competitive intensity increases rewards from pricing transparency. D) Competitive intensity increases the rewards from expertise.

\section{Data and empirical specification}

To test these hypotheses, we combine three data sources, each sampling Kenya and Uganda. First, we utilize data from an in-person, cross-sectional survey of over 4,400 mobile money agents. We combine this data with the precise locations of over 68,000 financial access and transportation points (including mobile money agents, banks, and bus stands) in the two countries. Finally, we integrate granular (per square kilometer) spatial estimates of population and poverty (with the latter defined as the number of people living on less than $\$ 2$ per day) in each given square kilometer.

\subsection{Agent network survey}

We use a large survey conducted by MicroSave, an organization focused on extending financial services to the poor in the developing world. MicroSave's Agent Network Accelerator (ANA) survey was conducted in Kenya and Uganda throughout 2013. Between 1,500 and 2,500 mobile money agents were surveyed in-person in each country by a team of professional surveyors. The surveys were designed to be nationally representative through three steps. First, the total number of agents to be surveyed within a given country was determined based on time and financial constraints. Next, surveys were apportioned to each operator in each district (analogous to a county in the United States) by multiplying the ratio of district population to national population by the operator's national customer base. Finally, in each district, a local team lead identified a representative 
enumeration area (EA). Once the EA was identified, surveyors were given mutually exclusive routes to walk, applying a "left-hand-rule" walk pattern, skipping a pre-determined number of agents on the left-hand side before attempting to interview the next agent. ${ }^{2}$ This pre-determined number was based on the number of agents the given operator had in the district, which was derived from the spatial census data described below. Each survey lasted between 30-60 minutes, varying due to interruptions by customers during the survey administration. As with many in-person surveys, there was a very high response rate (roughly 95\%). All data were point estimates of steady-state levels and were self-reported by the agents or observed directly by the surveyor. The interview covered a wide array of topics, including demographics and location (latitude and longitude), products and services offered, inventory management, revenue and commission structure, platform performance, training, monitoring, and support. From these data we glean independent variables StockoutRatio, SystemDownRatio, PricingTransparency, and Expertise, as well as controls Male, Tills, TillsRoot, Sunday, Dedicated, and OperatorG. Each of these variables is described in detail in the econometric specification subsection. From the 4,406 survey responses, we obtain our final cross-sectional survey dataset of 3,580 observations by dropping observations with missing values of the control variable Sunday (196), missing demand estimates (337), refusals to provide demand estimates (265), and obviously skewed estimates of SystemDown (28). The obviously skewed estimates of SystemDown were estimates of 100 or more lost transactions per day, on average, from system failure. These dropped observations represented the top $0.17 \%$ of all SystemDown data points, and were over 5 standard deviations greater than the mean (13). We test (and find support for) the robustness of our results to the inclusion of these dropped records through multiple imputation. We discuss and provide the results of this robustness test in Section 6 and the Appendix.

\subsection{Spatial census of financial access points}

We utilize data from fspmaps.com, a financial access mapping effort funded by the Bill \& Melinda Gates Foundation (BMGF). In 2012 and 2013, Brand Fusion, a research company based in South Africa, employed teams in Kenya and Uganda to collect geographic data. These teams canvassed both countries for financial service access points, recording their locations with GPS-enabled smartphones. The raw data behind fspmaps.com consists of the exact latitude and longitude coordinates of over 68,000 mobile money agents (with operator details), bank branches, and bus stands in Kenya and Uganda. Table 1 shows the collected geographic data breakdown by access-pointtype and country. The teams also supplemented every geographic data point with pictures of the

2 The "left (right)-hand-rule" is a common methodology for selecting stationary interviewees for in-person data collection. 
Balasubramanian and Drake: Service Quality, Competition, and Mobile Money Agent Demand

financial access point for validation. By combining the surveyed agent locations with the spatial census data through a process known as buffer analysis, we generate the independent variable DirectCompetition, as well as controls IndirectCompetition, Bank1km, and Bus1km.

\begin{tabular}{llll} 
& Kenya & Uganda & Total \\
\hline Mobile money agents & 48,524 & 17,889 & 66,413 \\
Bank branches & 1,221 & 477 & 1,698 \\
Bus stands & 613 & 121 & 734 \\
\hline \multicolumn{2}{c}{ Table 1 Table of geotagged financial access points }
\end{tabular}

\subsection{High-resolution spatial demographics}

Lastly, we draw upon spatial population and income data generated by WorldPop, an organization focused on creating high-quality maps for the humanitarian sector. In order to create these maps, WorldPop combines three sources of data: satellite imagery (Radarsat-1 country mosaics and Landsat Enhanced Thematic Maps); the Africover database containing geographic data on roads, land cover, and bodies of water; and country-level census data. The resulting integrated model generates precise population estimates for every square kilometer of Africa (Tatem et al. 2007). WorldPop used a similar method to develop a high-resolution spatial data layer of the population in povertythose consuming less than $\$ 2$ per day. To generate its poverty spatial data, WorldPop employs a process known as "Bayesian geostatistics" to integrate geocoded well-being surveys conducted by USAID (Demographic and Health Survey) and the World Bank (Living Standards Measurement Survey). The resulting data layer, like the general WorldPop data layer, has a resolution of 1 square kilometer (Tatem 2013). Figure 3 depicts a spatial data layer of the poor population in Kenya's Nyanza Province. The green circles depict buffers of 5, 10, and 15 kilometers (for ease of viewing) around bank branches, generated using a process called buffer analysis. Buffer analysis is a spatial analysis technique that generates circles of specified radii around points of interest (such as mobile money agents) and then calculates the number of other features of interest (such as the number of other agents and population counts) that fall within these circles. By combining the surveyed agent locations with the spatial demographic data, we generate control variables PopK $1 \mathrm{~km}$ and PovRatio1km through buffer analysis.

\subsection{Econometric specification}

Dependent variable From the survey data, we have point estimates of the steady-state number of successful transactions on a busy day $(T)$, the number of transactions denied due to stockouts $(S)$, and the number of transactions denied due to system failure $(F)$. We define demand as $D=$ $T+S+F$. We conduct an OLS regression on the natural logarithm of demand $(\log (\operatorname{Demand}))$. 


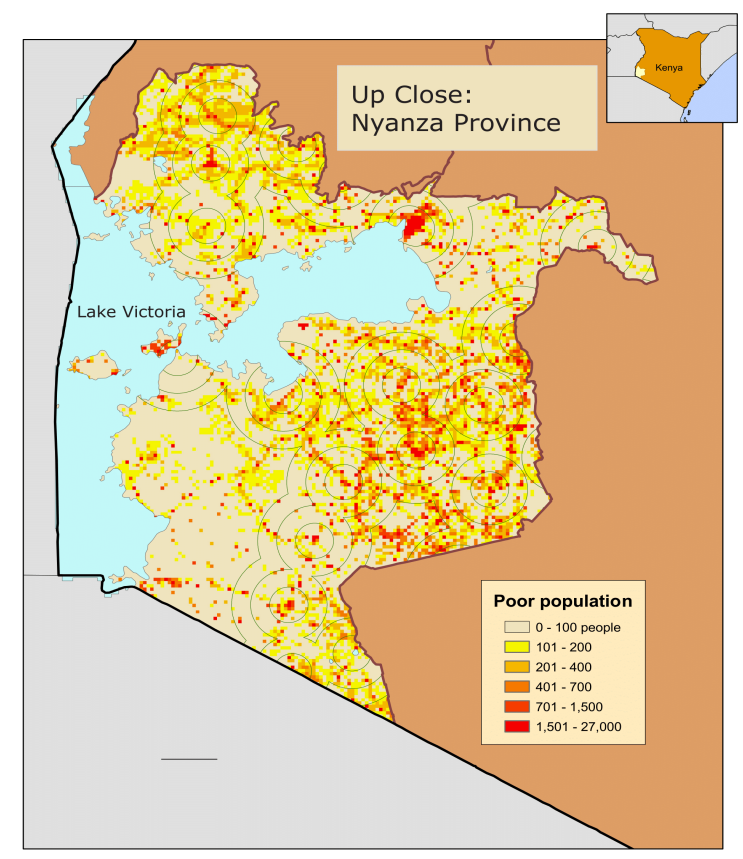

Figure 3 Spatial poor population and bank buffers in Kenya's Nyanza Province, adapted from BMGF (2012)

We log demand for two principle reasons. First, demand cannot be negative in this context (to be licensed, all agents must have at least 1 transaction per day). Secondly, using the log of demand simplifies the interpretation of estimated coefficients: a 1 unit change in an independent variable corresponds to a $\beta^{*} 100 \%$ change in demand.

Independent and interaction variables Our independent variables are listed as follows. StockoutRatio, the ratio of transactions denied due to stockouts to total demand is calculated as $S / D .{ }^{3}$ SystemDownRatio, the ratio of transaction denied due to system failures to total demand is calculated as $F / D$. DirectCompetition, our measure for competitive intensity, indicates the number of other agents primarily serving the same operator as a particular agent within 1 kilometer of that agent. PricingTransparency is an indicator variable that captures whether an agent has posted the tariff sheet (listing of transaction prices) prominently in the shop, with a 1 indicating that the agent posted the tariff sheet and a 0 indicating that the agent did not post the tariff sheet prominently in the shop. Expertise is an indicator variable that captures whether the agent correctly answered a difficult question about mobile money policy, with a 1 indicating that the agent correctly responded to the question (greater expertise), and a 0 indicating that they

\footnotetext{
${ }^{3}$ There is a structural positive relationship between StockoutRatio and $\log ($ Demand) as they are define here. For example, if we increase StockoutRatio, $\log ($ Demand) structurally increases, all else equal. As will become apparent in the next section, we hypothesize a negative relationship between StockoutRatio and $\log (\operatorname{Demand})$. Therefore, relatively to our hypotheses, this structure is conservative. For such a hypothesis to be supported, an increase in StokcoutRatio must decrease $\log ($ Demand $)$ sufficiently to overcome this structural positive relationship.
} 
Balasubramanian and Drake: Service Quality, Competition, and Mobile Money Agent Demand

Article submitted to Manufacturing $\&$ Service Operations Management

did not respond correctly to the question (lesser expertise). To estimate the impact of competition on service quality, we include interactions between DirectCompetition and StockoutRatio, PricingTransparency, and Expertise.

Control variables We include several controls that are likely to impact demand. Male indicates agent gender, with a 1 indicating male and a 0 indicating female. Dedicated indicates whether the agent is solely dedicated to the mobile money business or whether they operate another retail business on the side, with a 1 indicating dedication to solely mobile money transactions and a 0 indicating that the agent operates other businesses in parallel. Sunday indicates whether the agent is open for business on Sunday, with a 1 indicating that the agent operates on Sunday and a 0 if the agent does not operate on Sunday. Tills is a variable that takes integer values greater than 0 to indicate the number of agent tills (i.e., "virtual cash registers") the agent has. TillsRoot is the square root of the number of tills, and is included to capture potential diminishing returns gained from each incremental till. PopK $1 \mathrm{~km}$ and PovRatio $1 \mathrm{~km}$ are the population (in thousands) within a 1 kilometer radius of an agent and the ratio of those people who live on less than $\$ 2$ a day, respectively. IndirectCompetition is the number of agents primarily serving other operators in a 1 kilometer radius of an agent. Bank $1 \mathrm{~km}$ is the number of bank branches in a 1 kilometer radius of an agent; banks are a major resource in helping agents rebalance inventory (get cash and/or e-float). Bus1km is the number of major bus stops in a 1 kilometer radius of an agent; this is a proxy for the difficulty of transit in the vicinity of the agent. NumUsers $M$ is a measure of the number of users (in millions) that subscribe to the operator network that an agent serves. CountryAge is a measure of market maturity: it measures the number of months between when the first mobile money service launched in a particular country and June 2013 (when the survey was conducted). Finally, there are $5(+1)$ indicator variables for each operator/brand represented in the sample, which capture differences across operators not accounted for by our independent variables or the controls above.

\section{Results}

Summary statistics are presented in the appendix. Table A1 includes means, standard deviations, and differences in means. Table A2 presents pair-wise correlation statistics. Generally speaking, Kenya leads Uganda in mobile money market development. The average agent across the sample faces a demand for approximately 56 transactions on a busy day, and we note that Kenya leads on this metric. We also note that the StockoutRatio in Kenya is lower than in Uganda, perhaps suggesting that as a market matures, agents stock out less frequently. This pattern is even more pronounced with SystemDownRatio: Ugandan agents lose twice as much demand to platform failures than their Kenyan counterparts. Overall, 26\% of the consumer transactions demanded 
were denied, resulting in an average service level of less than $74 \%$. Kenya leads with an average $81 \%$ service level versus the Ugandan average of $67 \%$. With regard to PricingTransparency, the vast majority of agents are transparent with pricing, led by Kenya. With regard to Expertise, approximately $81 \%$ of agents passed an expertise test, with Kenya lagging slightly. Competition among agents, as measured by the number of other agents that directly compete with each agent, is lower in Uganda than in Kenya. This is reversed for the number of indirectly competing agents (agents serving other operators), where the average Ugandan agent has more indirectly competing agents within 1 kilometer on average than their Kenyan counterparts.

The sample contained slightly more female agents than male agents, approximately equal in both countries. Additionally, just under half of the sampled agents operated on Sunday, with Ugandan agents more likely to operate on Sunday than Kenyan agents. Just over half of agents run a dedicated mobile money business. The average Kenyan agent serves an operator that is used by many more people ( $50 \%$ larger) than the average Ugandan agent's operator. Another proxy for market development is CountryAge, which is the number of months between when the first mobile money operator in the country launched and June 2013; Kenya began more than 2 years ahead of Uganda. We also note that even in Kenya, the market is relatively young-Safaricom, the global leader of mobile payment providers, launched less than 7 years ago. We also note that Kenyan agents in the sample locate on average in more densely populated areas than Ugandan agents, while Ugandan agents are much more likely to be located in areas of high poverty concentration than Kenyan agents. Finally, we see that Kenyan agents in the sample on average have at least twice as many bank branches and bus-stands within a 1 kilometer radius than Ugandan agents. This is reflective of the fact that Kenya is more economically developed than Uganda, and thus its financial and transportation infrastructure is more developed than its neighbor.

The results from five OLS regressions are presented in Table A3. The first model excludes interactions with DirectCompetition. The next three models each include a single interaction term, and the final model includes all three interaction terms. ${ }^{4}$ The discussion that follows is based on the full model unless otherwise noted. Robust standard errors are reported, as the Breusch-Pagan test indicated the presence of heteroskedasticity.

To test whether the results presented in Table A3 are robust to the inclusion of dropped observations, we utilize multiple imputation (predictive mean matching) to predict missing values. We then estimate $\log$ (demand) using the full set of 4,406 survey observations. Results for this test are presented in Table A4 in the Appendix. While estimated coefficient values vary slightly relative to the base models, the results presented above hold (both directionally and in significance).

\footnotetext{
${ }^{4}$ Models 2 through 4 are provided so that estimated coefficients for the interaction terms in the full model can be compared to those in the models that isolate a single interaction to ensure that results in the full model are not skewed by potential multi-colinearity (given that all three interaction terms include competitive intensity).
} 


\subsection{Service reliability}

Our first set of hypotheses focused on the effect of service reliability through its inverse, denied transactions from stockouts and from system failures. From Table A3, we note that the coefficient on StockoutRatio is large, negative, and statistically significant, in both model 1 (without interaction terms) and model 5 (with interaction terms). Using the result from model 5 , the coefficient on StockoutRatio can be interpreted as follows: for an agent with zero direct competitors in her 1 kilometer catchment area, a 0.1 increase in StockoutRatio (equivalently, a 10 percentage point increase in stockout percentage) results in a estimated $5.55 \%$ drop in steady-state demand. Figure 4 depicts a plot of predicted values (with 95\% confidence intervals) and estimates of $\log (\operatorname{Demand})$ over the range of StockoutRatio values. ${ }^{5}$

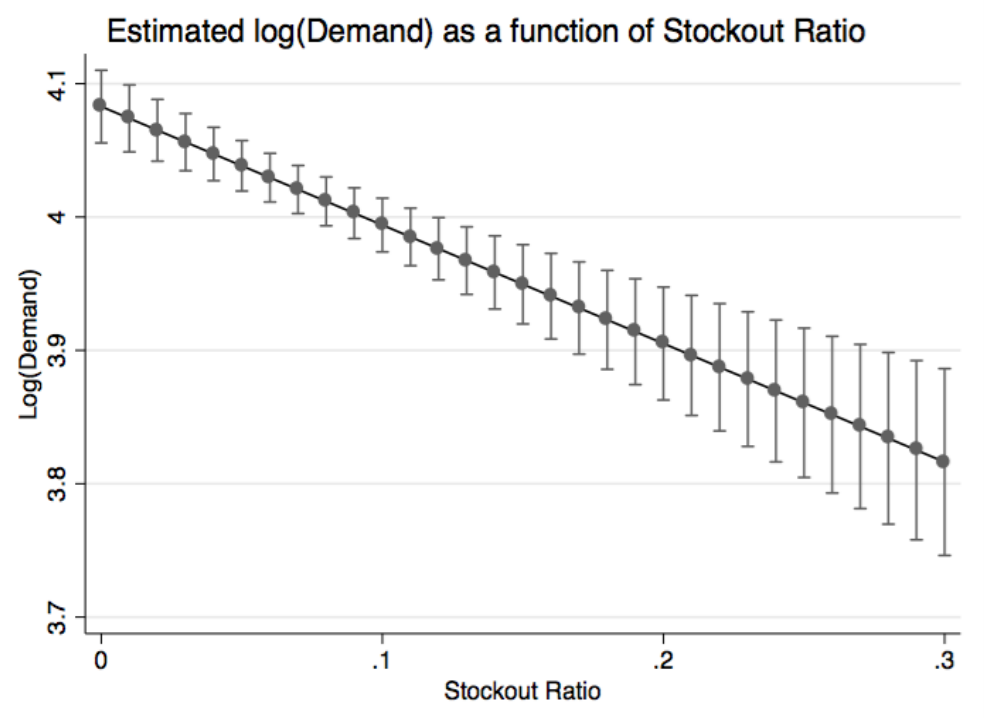

Figure 4 Plot of stockout effect on demand

The SystemDownRatio coefficient is much smaller in magnitude than StockoutRatio, and is not statistically significant. We test whether SystemDownRatio is equal to StockoutRatio. The F-statistic for this test (the square of the t-statistic) is 8.83, which results in rejecting the null $(\mathrm{p}<0.01)$ hypothesis that the two coefficients are equal, supporting hypothesis $1 \mathrm{~b}$. These results suggest that customers react more negatively to denied transactions due to stockouts than they do for denied transactions due to system failure.

\footnotetext{
${ }^{5}$ These estimated values are generated by using model 5 to generate a predicted value of $\log (\operatorname{Demand})$ for each observation by plugging in true values of all right-hand side variables except for StockoutRatio (using the value of interest) and then averaging these predicted values of $\log ($ Demand $)$.
} 


\subsection{Pricing transparency and agent expertise}

We next test the effect of service quality measures on demand: pricing transparency and expertise. The data support hypothesis $2 \mathrm{a}$. The main effect of pricing transparency (non-transparency) is an increase (decrease) in the agent's steady-state demand. The data also support hypothesis $2 \mathrm{~b}$. As a main effect, agent expertise increases steady-state demand. The magnitudes of these effects are also notable; the presence of a tariff sheet increases demand by over $12 \%$ and the ability to answer a difficult question about mobile money policy increases demand by over $10 \%$.

\subsection{Competition}

The data support hypothesis 3a, competitive intensity attenuates steady-state demand. Figure 5 depicts the estimated values (with 95\% confidence intervals) of $\log$ (Demand) as the level of competitive intensity varies.

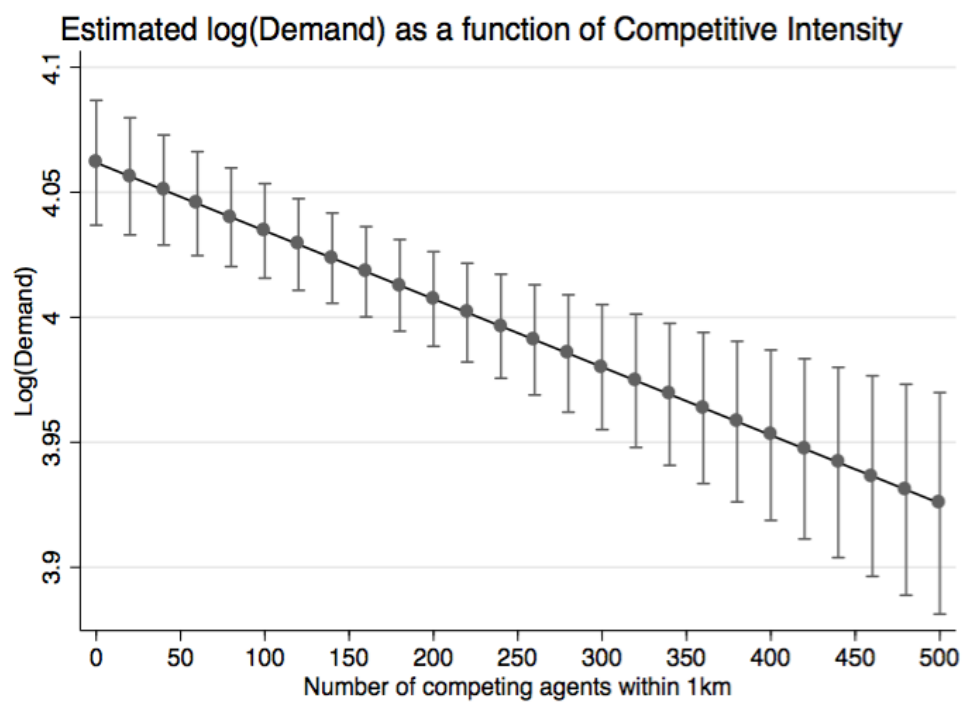

Figure 5 Plot of competitive intensity effect on demand

Our final three hypotheses relate to how competitive intensity interacts with dimensions of service quality: stockouts (i.e., service failure), pricing transparency, and expertise. The coefficient on DirectCompetition x StockoutRatio is significant and negative, which supports hypothesis 3b: proximate competition significantly exacerbates the stockout effect. The coefficient on DirectCompetition x PricingTransparency is not statistically significant. Hypothesis 3c is therefore not supported: we do not find that competitive intensity augments the pricing transparency effect. Finally, the coefficient on DirectCompetition x Expertise is significant and positive, supporting hypothesis $3 \mathrm{~d}$ : competitive intensity augments the expertise effect. These latter two effects are illustrated in Figures 6a and 6b. In Figure 6a, we see the estimated $\log ($ Demand) values as 
Balasubramanian and Drake: Service Quality, Competition, and Mobile Money Agent Demand

PricingTransparency and DirectCompetition are varied. The pricing transparency effect, the gap between the two lines, is clearly visible, but there is not a difference in the slopes of the two lines (which would be evidence of an interaction between competitive intensity and pricing transparency). Figure 6b illustrates estimates of logDemand as DirectCompetition and Expertise are varied. Analogously to the pricing transparency effect, we clearly see the expertise effect in the gap between the two lines. However in Figure $6 \mathrm{~b}$ a difference in the slopes of the two lines is also visible, evidence of an interaction between competitive intensity and expertise.

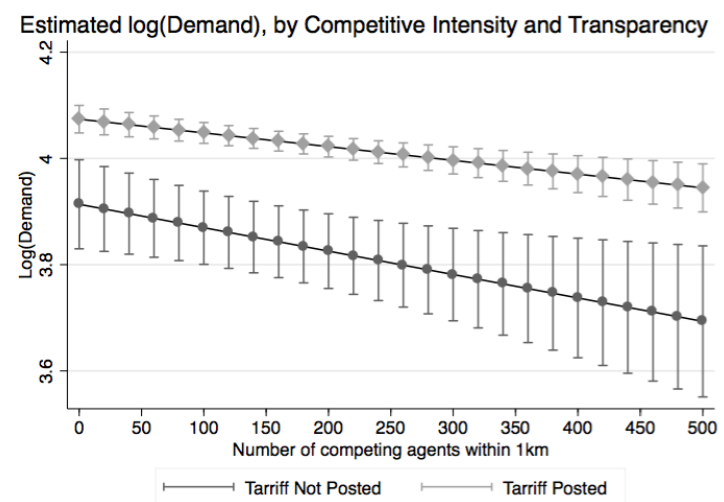

(a) Pricing transparency effects

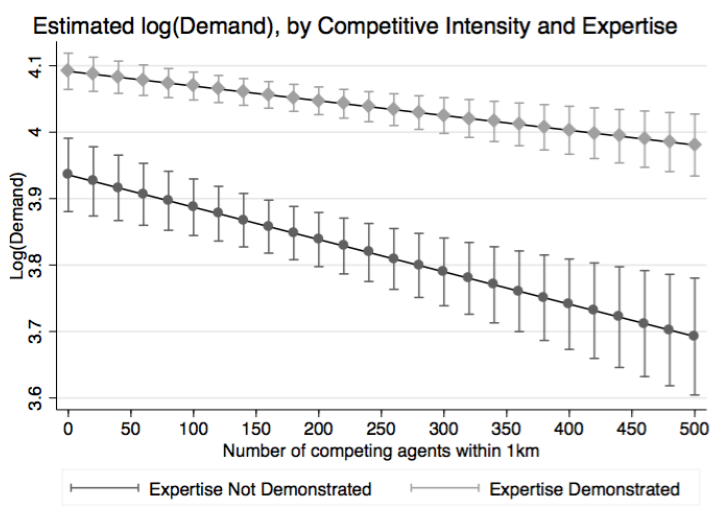

(b) Expertise effects

Figure 6 Plots of predicted demand as a function of competitive intensity and service quality measures

\section{Discussion}

Our results provide insight on how service quality and competition affect demand in a new and important operations context, particularly relevant to the base of the pyramid community. Specifically, we investigate the effect of stockouts, pricing transparency, and mobile money agents' expertise. We also investigate the effect of competitive intensity on demand, both directly and as a moderator of service quality effects. Furthermore, we empirically demonstrate the notion that, beyond the potential immediate lost sale, there is a long-term cost to stockouts in the form of lost steady-state demand. We also see a reward (cost) for pricing transparency (non-transparency) and expertise (lack of expertise). The cost associated with stockouts and the rewards associated with expertise are magnified in the face of competition.

This paper provides empirical support to Schwartz's (1966) theoretical prediction that stockouts would alter future demand. As Anderson et al. (2006) showed was the case with mail-order catalogs, we find that mobile money agents in Kenya and Uganda who stock out more often experience lower steady-state demand. We find that for the average agent, a $1 \%$ increase in stockouts $(0.01$ increase 
in StockoutRatio) corresponds to a reduction in demand of approximately $0.85 \%$. The fact that the stockout effect is large is not surprising, given the potential urgency associated with the service. For example, Jack and Suri (2014) show that mobile money had the effect of significantly widening and enhancing informal insurance networks, enabling family and friends to send users more money more efficiently in times of crisis (Jack and Suri 2014).

We also demonstrate that the magnitude of the stockout effect is augmented in the face of competitive intensity. Figure 7 illustrates this finding. While an agent who faces no competition loses approximately $0.55 \%$ of demand for a $1 \%$ increase in stockouts, an agent who faces 170 agents (roughly the 75 th percentile) incurs a $0.95 \%$ reduction in demand for every $1 \%$ increase in stockouts. In this case, greater competitive intensity nearly doubles the stockout effect.

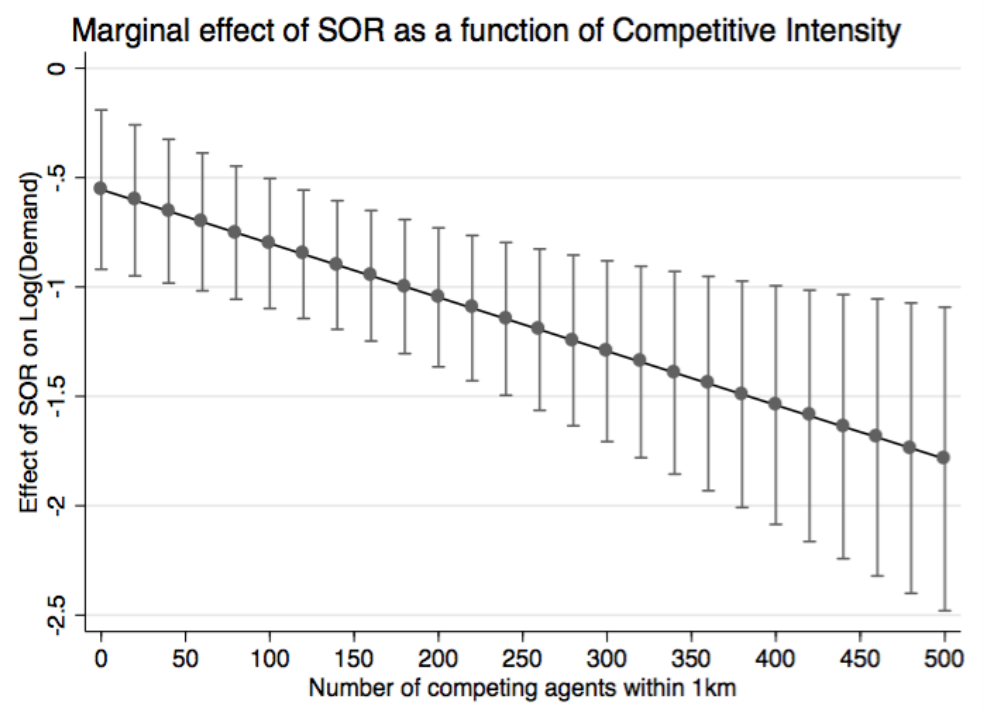

Figure 7 Plot of marginal effect of StockoutRatio (SOR) on demand as a function of Competitive Intensity

Furthermore, we demonstrate the stockout effect is larger than the system-down effect; agents lose more demand for stocking out than for system failures, even though the net result is the samea denied transaction. This result is roughly in line with Taylor (1994), who finds that attribution of blame for airline delays is associated with the degree to which customers believe the airline had control over the delay. Our result takes this finding a step further: customers do not decrease their demand for an agent's services in response to an operator's failure. To the extent that this generalizes to other contexts, this result has managerial implications to firms with franchised or otherwise contracted operations. When the franchisee/contractor/reseller can successfully demonstrate to customers that a service failure was not the result of her own failure, but rather the failure 
Balasubramanian and Drake: Service Quality, Competition, and Mobile Money Agent Demand

of a supplier/provider, then some, if not all of the demand reduction associated with service failure might be avoided.

Agents will also want to account for lost steady-state demand as a consequence of stockouts when deciding on their cash and e-float inventory levels. Determining agents' optimal inventory policy given operator commission rates and this loss of future sales due to stockouts is the focus of future work.

This paper adds empirical support to the notions that customers reward both pricing transparency and expertise. In the mobile money context, agents enjoy significant rewards for both pricing transparency and expertise as a main effect. We also add empirical evidence to the intuitive notion that competitive intensity dampens firm demand. Oliveras and Cachon (2009) termed this the "sales effect," but we refer to it as the "competition effect" to make it clear that competitive intensity is the driver because many of our independent and control variables affect sales. We find that a competition effect is indeed present in the mobile money context. Perhaps more interesting is our finding that this effect is greatly augmented when competitive intensity is interacted with stockout ratio. Based on the coefficient for DirectCompetition and its interaction with StockoutRatio (table A3), for an agent that has a stockout ratio of 0.1 (10\% of total demand is not satisfied due to stockout), the competition effect is augmented by over $50 \%$. Agents that deny $15 \%$ of their demand due to stockouts will face a competitive effect augmented by over $80 \%$. We also find that expertise interacts with competition: the rewards for expertise increase in the face of greater competitive intensity. However, our data suggest that pricing transparency does not interact with competitive intensity. This suggests that pricing transparency is not a dimension of competition in mobile money, only that some fraction of the (potential) customer base simply will not do business with non-transparent agents, whether or not there are other competitors around. Using the operations strategy terminology coined by Hill (1993), pricing transparency may be an "order qualifier" for a segment of the market - these customers will not even consider agents who are not transparent with prices. Our data suggest that both reliability and expertise act as "order winners" for a segment of customers - all else equal, these customers choose more reliable and more expert agents among their set of "qualified" agents.

For mobile money agents, this model allows for the calculation of the approximate long-term cost of service level decisions: the loss of demand to be expected for a given service level. This value (along with additional parameters) can be used to generate an agent's optimal inventory control policy. In informal interviews, agents in Kenya indicated that they were generally concerned by proximate agents serving the same operator, especially when the interviewed agent had experienced recent stockout service failures. By demonstrating competition's effect on demand, as well as an 
interaction between competition and stockouts, this paper provides empirical support to these agents' intuition.

For mobile money operators, this work has several implications. First, it can be useful in planning agent network expansion, as it yields a prediction of demand a potential agent may face if she began operating in a particular location. Similarly, our empirical model can inform the optimal placement and number of agents in a certain geography - enough to capture demand (and potentially to inspire higher service levels), but not so many to jeopardize agents' commercial viability. Understanding the stockout effect (and its moderators) is useful in this process. It also informs guidance and/or policies operators should put in place, such as mandatory and rigorously enforced tariff sheet posting and rigorous training to ensure knowledge of policies.

This analysis, like other analyses using survey data, suffers from potential bias: demand, stockout, and system failure data were all self-reported estimates by the agent. To the extent that agents thought their operators might see the results (even though they were promised confidentiality by the third party research firm, and this confidentiality was honored), agents' estimates of stockouts might be biased downwards. However, there is no evidence to indicate that some agents might be more biased than others. There is also a limitation in regards to our spatial variables. First, the catchment areas are defined in terms of "as-the-crow-flies" distance, rather than true travel time. Secondly, the service quality of nearby competing agents very likely affects the impact of a particular agent's service quality on their steady-state demand. Unfortunately, our dataset does not capture a quality metric such as the one that may have proven useful in this case. Finally, our dataset limited our measure of demand to a raw count of transactions. An interesting additional dimension of analysis would consider the value of these transactions as well.

\section{Conclusions}

Mobile money is a rapidly growing industry that has potential to dramatically improve the lives of the poor in a multitude of ways, including through facilitating more efficient cash transfers after emergencies. We begin to explore this industry by characterizing the demand faced by mobile money agents, as well as determining factors that drive (or dampen) demand for cash-in and cashout transactions. We find that an agent's reduction in demand associated with stocking out of cash or e-float is economically and statistically significant. However, agents do not experience a demand reduction when they are unable to fulfill demand due to a system outage. Mobile money consumers, therefore, appear to differentially ascribe transaction failure ownership. Agents who are transparent with transaction pricing experience relatively greater demand. Agents who are relatively more knowledgeable not only see relatively greater demand, but also seem to reap benefits from this expertise in the face of competition. Finally, we find that the demand reduction associated 
Balasubramanian and Drake: Service Quality, Competition, and Mobile Money Agent Demand

with stockouts is exacerbated by the presence of competitors, indicating that agents' inventory management (as experienced through stockout rate) is another important competitive dimension in this context.

\section{Acknowledgments}

Sincerest thanks to Mike McCaffrey and Leena Anthony of MicroSave's Agent Network Accelerator for being so open with data from their survey, as well as the Research Solutions Africa surveyor team. Many thanks also to Eric Kramak and Todd Slind of SpatialDev for facilitating access to the raw spatial data behind fspmaps.com, as well as Andy Tatem and the WorldPop team for the spatial population and poverty data. The authors are also very grateful to Jake Kendall and Daniel Radcliffe of the Bill \& Melinda Gates Foundation for connecting us with MicroSave and Karina Nielsen of CGAP for connecting us with SpatialDev. Thanks also to Giovanni Zambotti and Stacy Bogan of Harvard University's Center for Geographic Analysis, as well as Xiang Ao and Jonathon Polit of Harvard Business School's Research Computing Services for their invaluable help in preparing and analyzing data. The authors are grateful to the Harvard Business School Doctoral Programs Office for generous research support.

\section{References}

Agrawal, M. 2009. Mobile Money Transfer. URL http://www.telecomcircle.com/2009/05/ mobile-money-transfer-mmt/. Telecom Circle Blog.

Aker, J., R. Boumnijel, A. Mcclelland, N. Tierney. 2011. Zap It to Me: The Short-Term Impacts of a Mobile Cash Transfer Program. Center for Global Development Working Paper 268.

Allon, G., A. Federgruen, M. Pierson. 2011. How much is a reduction of your customers' wait worth? An empirical study of the fast-food drive-thru industry based on structural estimation methods. Manufacturing 83 Service Operations Management .

Anderson, E., G. Fitzsimons, D. Simester. 2006. Measuring and Mitigating the Costs of Stockouts. Management Science 52(11) 1751-1763.

Batista, C., P. Vicente. 2013. Introducing Mobile Money in Rural Mozambique: Evidence from a Field Experiment. Working Paper.

BCG. 2011. The Socio-Economic Impact of Mobile Financial Services. Tech. Rep. April. Boston Consulting Group.

BMGF. 2012. Geospatial Analysis for Financial Inclusion Tracking. URL http://goo.gl/RGaOkM. Mobile Money for the Unbanked Blog.

Buell, R., M. Norton. 2011. The Labor Illusion: How Operational Transparency Increases Perceived Value. Management Science 57(9) 1564-1579. 
Buku, M., M. Meredith. 2013. Safaricom and M-PESA in Kenya: Financial Inclusion and Financial Integrity. Washington Journal of Law, Technology, and the Arts 8(3).

Collins, D., S. Rutherford, J. Morduch. 2009. Portfolios of the Poor. Princeton University Press.

Craig, N., N. Dehoratius, A. Raman. 2014. The Impact of Supplier Inventory Service Level on Retailer Demand in the Supply Chain for Functional Apparel Items. Harvard Business School Working Paper No. 11-034.

Demirguc-kunt, A., L. Klapper. 2012. Measuring Financial Inclusion The Global Findex Database. World Bank Policy Research Working Paper 6025.

Dhaliwal, D., O. Li, A. Tsang, Y. Yang. 2011. Voluntary Nonfinancial Disclosure and the Cost of Equity Capital: The Initiation of Corporate Social Responsibility Reporting. The Accounting Review 86(1) $59-100$.

Gamerschlag, R., K. Möller, F. Verbeeten. 2010. Determinants of Voluntary CSR Disclosure: Empirical Evidence from Germany. Review of Managerial Science 5(2-3) 233-262.

Garbarino, E., O. Lee. 2003. Dynamic pricing in internet retail: Effects on consumer trust. Psychology and Marketing 20(6) 495-513.

Gold, S., R. Hahn, S. Seuring. 2013. Sustainable supply chain management in Base of the Pyramid food projects: A path to triple bottom line approaches for multinationals? International Business Review 22(5) 784-799.

Groupe Speciale Mobile Association. 2013. State of the Industry: Mobile Financial Services for the Unbanked. Tech. rep.

Helms, B. 2006. Access for All. Tech. rep. Working Paper, Consultative Group to Assist the Poor.

Hill, T. 1993. Manufacturing Strategy: The Strategic Management of the Manufacturing Function. MacMillian.

Intermedia. 2013. Mobile Money Use, Barriers, and Opportunities. Tech. Rep. February.

Jack, W., T. Suri. 2014. Risk Sharing and Transactions Costs: Evidence from Kenya's Mobile Money Revolution . American Economic Review 104(1) 183-223.

Kalkanci, B., E. Plambeck. 2012. Measurement and Improvement of Social and Environmental Performance under Voluntary versus Mandatory Disclosure. Working Paper.

Kendall, J. 2011. An Emerging Platform: From Money Transfer System to Mobile Money Ecosystem.

Mas, I. 2010. Savings for the Poor. World Economics 11(4) 1-12.

Morawczynski, O. 2009. Poor People Using Mobile Financial Services: Observations on Customer Usage and Impact from M-PESA. Brief, Consultative Group to Assist the Poor.

Olivares, M., G. Cachon. 2009. Competing Retailers and Inventory: An Empirical Investigation of General Motors' Dealerships in Isolated U.S. Markets. Management Science 55(9) 1586-1604. 
Parasuraman, A., V. Zeithaml. 1988. SERVQUAL: A Multiple-Item Scale for Measuring Consumer Perceptions of Service Quality. Journal of Retailing 64(1).

Prahalad, C. K., A. Hammond. 2002. Serving the Worlds Poor, Profitably. Harvard Business Review (September).

Reeves, C., D. Bednar. 1994. Defining Quality: Alternatives and Implications. Academy of Management Review 19(3) 419-445.

Schwartz, B. 1966. A new approach to stockout penalties. Management Science 12(12) B-538 - B-544.

Singh, J., D. Sirdeshmukh. 2000. Agency and Trust Mechanisms in Consumer Satisfaction and Loyalty Judgments. Journal of the Academy of Marketing Science 28(1) 150-167.

Sodhi, M., C. Tang. 2011. Social enterprises as supply-chain enablers for the poor. Socio-Economic Planning Sciences 45(4) 146-153.

Sun, P., C. Lin. 2010. Building customer trust and loyalty: an empirical study in a retailing context. The Service Industries Journal 30(9) 1439-1455.

Tatem, A. 2013. Development of Pilot High-Resolution Gridded Poverty Surfaces: Methods Working Paper.

Tatem, A., A. Noor, C. von Hagen, Antonio Di Gregorio, S. Hay. 2007. High resolution population maps for low income nations: combining land cover and census in East Africa. PloS one 2(12) e1298.

Taylor, S. 1994. Waiting for Service: The Relationship Between Delays and Evaluations of Service thanks. Journal of Marketing 58(2) 56-69.

Toffel, M., E. Reid. 2009. Responding To Public And Private Politics : Corporate Disclosure Of Climate Change Strategies. Strategic Management Journal 1178(June) 1157-1178.

Walter, C., J. Grabner. 1975. Stockout cost models: Empirical tests in a retail situation. The Journal of Marketing 39(3) 56-60.

Wright, G., L. Mutesasira. 2001. The Relative Risks of Savings to the Poor. Small Enterprise Development 12 (3) 33-45. 


\section{APPENDIX}

\begin{tabular}{|c|c|c|c|c|}
\hline \multirow{3}{*}{ logDemand } & Overall & Kenya & Uganda & Difference \\
\hline & 4.03 & 4.05 & 4.00 & $0.05^{* *}$ \\
\hline & {$[0.65]$} & {$[0.69]$} & {$[0.59]$} & \\
\hline \multirow[t]{2}{*}{ StockoutRatio } & 0.07 & 0.06 & 0.07 & $-0.01 * *$ \\
\hline & {$[0.07]$} & {$[0.06]$} & {$[0.07]$} & \\
\hline \multirow[t]{2}{*}{ SystemDownRatio } & 0.19 & 0.13 & 0.26 & $-0.13^{* *}$ \\
\hline & {$[0.13]$} & {$[0.10]$} & {$[0.13]$} & \\
\hline \multirow[t]{2}{*}{ PricingTransparency } & 0.92 & 0.96 & 0.88 & $0.08^{* *}$ \\
\hline & {$[0.26]$} & {$[0.20]$} & {$[0.32]$} & \\
\hline \multirow[t]{2}{*}{ Expertise } & 0.81 & 0.78 & 0.84 & $-0.06^{* *}$ \\
\hline & {$[0.39]$} & {$[0.41]$} & {$[0.37]$} & \\
\hline \multirow[t]{2}{*}{ DirectCompetition } & 135.51 & 144.74 & 124.26 & $20.48^{* *}$ \\
\hline & {$[177.37]$} & {$[171.56]$} & {$[183.64]$} & \\
\hline \multirow[t]{2}{*}{ Male } & 0.44 & 0.44 & 0.44 & 0.00 \\
\hline & {$[0.50]$} & {$[0.50]$} & {$[0.50]$} & \\
\hline \multirow[t]{2}{*}{ CountryAge } & 64.73 & 76.00 & 51.00 & $25.00 * *$ \\
\hline & {$[12.44]$} & {$[0.00]$} & {$[0.00]$} & \\
\hline \multirow[t]{2}{*}{ NumUsersMM } & 10.84 & 13.51 & 7.59 & $5.92^{* *}$ \\
\hline & {$[5.28]$} & {$[4.52]$} & {$[4.22]$} & \\
\hline \multirow[t]{2}{*}{ Sunday } & 0.47 & 0.44 & 0.50 & $-0.06^{* *}$ \\
\hline & {$[0.50]$} & {$[0.50]$} & {$[0.50]$} & \\
\hline \multirow[t]{2}{*}{ Dedicated } & 0.43 & 0.42 & 0.44 & $-0.02^{+}$ \\
\hline & {$[0.50]$} & {$[0.49]$} & {$[0.50]$} & \\
\hline \multirow[t]{2}{*}{ Tills } & 1.12 & 1.04 & 1.21 & $-0.17 * *$ \\
\hline & {$[0.59]$} & {$[0.34]$} & {$[0.78]$} & \\
\hline \multirow[t]{2}{*}{ TillsRoot } & 1.04 & 1.01 & 1.08 & $-0.07 * *$ \\
\hline & {$[0.18]$} & {$[0.11]$} & {$[0.24]$} & \\
\hline \multirow[t]{2}{*}{ IndirectCompetition } & 70.00 & 62.24 & 79.45 & $-17.21^{* *}$ \\
\hline & {$[182.67]$} & {$[219.25]$} & {$[123.76]$} & \\
\hline \multirow[t]{2}{*}{ PopK1km } & 27.04 & 31.58 & 21.50 & $10.08^{* *}$ \\
\hline & {$[34.00]$} & {$[41.53]$} & {$[20.21]$} & \\
\hline \multirow[t]{2}{*}{ PovRatio1km } & 0.19 & 0.08 & 0.34 & $-0.26^{* *}$ \\
\hline & {$[0.18]$} & {$[0.10]$} & {$[0.15]$} & \\
\hline \multirow[t]{2}{*}{ Bank1km } & 7.85 & 10.28 & 4.89 & $5.39^{* *}$ \\
\hline & {$[15.92]$} & {$[19.80]$} & {$[8.29]$} & \\
\hline \multirow[t]{2}{*}{ Bus1km } & 4.18 & 6.59 & 1.25 & $5.34^{* *}$ \\
\hline & {$[15.05]$} & {$[19.89]$} & {$[2.16]$} & \\
\hline
\end{tabular}

Table A1 Summary statistics: means, standard deviations (in brackets), and differences in means 


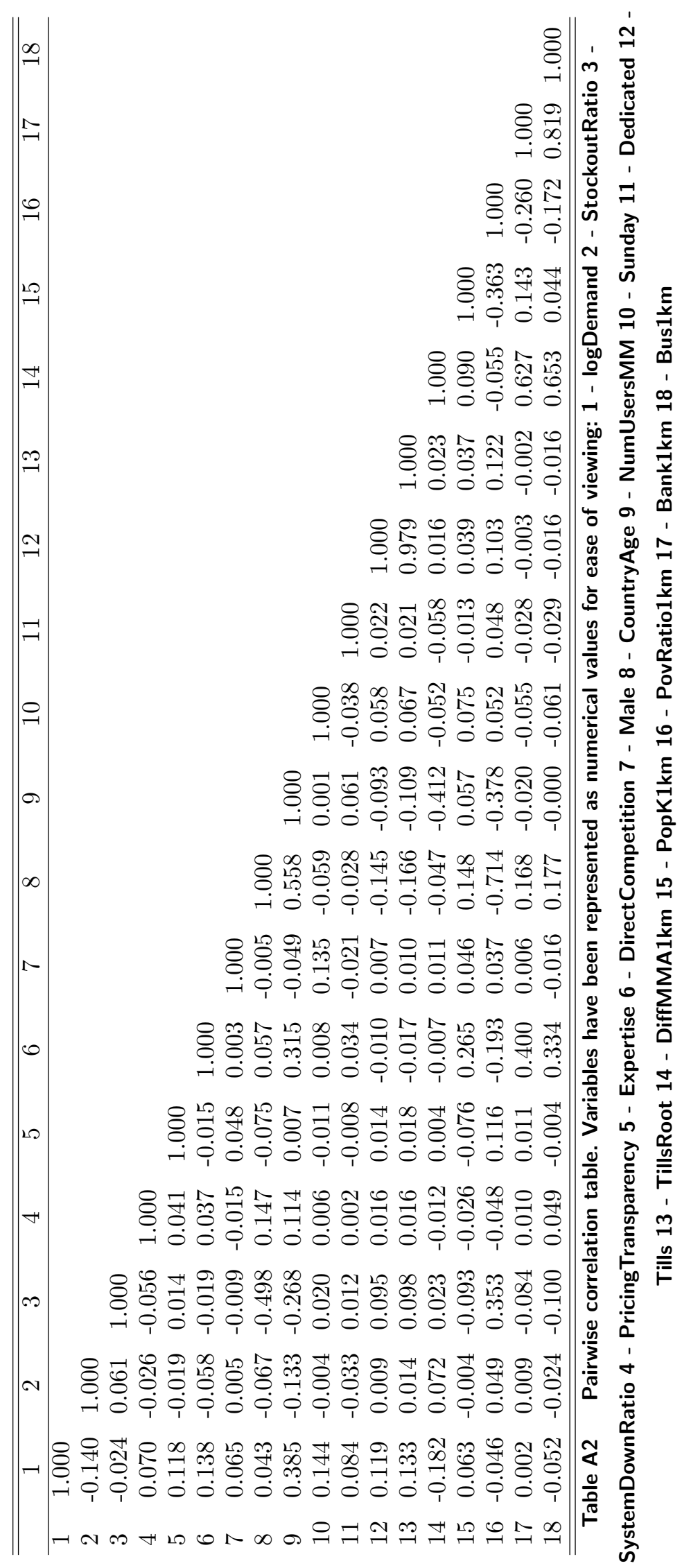




\begin{tabular}{|c|c|c|c|c|c|}
\hline & $(1)$ & $(2)$ & $(3)$ & $(4)$ & $(5)$ \\
\hline \multirow[t]{2}{*}{ StockoutRatio (SOR) } & $-0.825^{* *}$ & $-0.541^{* *}$ & $-0.827^{* *}$ & $-0.818^{* *}$ & $-0.555^{* *}$ \\
\hline & $(0.150)$ & $(0.186)$ & $(0.150)$ & $(0.150)$ & $(0.186)$ \\
\hline \multirow[t]{2}{*}{ SystemDownRatio } & 0.0635 & 0.0574 & 0.0630 & 0.0580 & 0.0525 \\
\hline & $(0.0884)$ & $(0.0886)$ & $(0.0884)$ & $(0.0885)$ & $(0.0887)$ \\
\hline \multirow[t]{2}{*}{ PricingTransparency (PT) } & $0.136^{* *}$ & $0.137^{* *}$ & $0.118^{* *}$ & $0.139^{* *}$ & $0.122^{* *}$ \\
\hline & $(0.0367)$ & $(0.0366)$ & $(0.0454)$ & $(0.0367)$ & $(0.0450)$ \\
\hline \multirow[t]{2}{*}{ Expertise (E) } & $0.143^{* *}$ & $0.141^{* *}$ & $0.144^{* *}$ & $0.103^{* *}$ & $0.106^{* *}$ \\
\hline & $(0.0233)$ & $(0.0232)$ & $(0.0233)$ & $(0.0310)$ & $(0.0311)$ \\
\hline \multirow[t]{2}{*}{ DirectCompetition } & $-0.000263^{* *}$ & -0.0000968 & $-0.000407^{*}$ & $-0.000499^{* *}$ & $-0.000455^{*}$ \\
\hline & $(0.0000593)$ & $(0.0000847)$ & $(0.000185)$ & $(0.000120)$ & $(0.000214)$ \\
\hline \multirow[t]{2}{*}{ SOR x DirectCompetition } & & $-0.00264^{* *}$ & & & $-0.00246^{* *}$ \\
\hline & & $(0.000859)$ & & & $(0.000862)$ \\
\hline \multirow[t]{2}{*}{ PT x DirectCompetition } & & & 0.000154 & & 0.000151 \\
\hline & & & $(0.000188)$ & & $(0.000182)$ \\
\hline \multirow[t]{2}{*}{ E x DirectCompetition } & & & & $0.000288^{*}$ & $0.000252^{*}$ \\
\hline & & & & $(0.000124)$ & $(0.000123)$ \\
\hline \multirow[t]{2}{*}{ Male } & $0.0882^{* *}$ & $0.0883^{* *}$ & $0.0879^{* *}$ & $0.0888^{* *}$ & $0.0886^{* *}$ \\
\hline & $(0.0187)$ & $(0.0186)$ & $(0.0187)$ & $(0.0187)$ & $(0.0186)$ \\
\hline \multirow[t]{2}{*}{ CountryAge } & $-0.0708^{*}$ & $-0.0709^{*}$ & $-0.0708^{*}$ & $-0.0711^{*}$ & $-0.0711^{*}$ \\
\hline & $(0.0289)$ & $(0.0287)$ & $(0.0290)$ & $(0.0285)$ & $(0.0284)$ \\
\hline \multirow[t]{2}{*}{ NumUsersMM } & $0.398^{+}$ & $0.399^{+}$ & $0.398^{+}$ & $0.399^{+}$ & $0.400^{+}$ \\
\hline & $(0.227)$ & $(0.225)$ & $(0.227)$ & $(0.223)$ & $(0.223)$ \\
\hline \multirow[t]{2}{*}{ Sunday } & $0.144^{* *}$ & $0.144^{* *}$ & $0.144^{* *}$ & $0.144^{* *}$ & $0.144^{* *}$ \\
\hline & $(0.0185)$ & $(0.0185)$ & $(0.0185)$ & $(0.0185)$ & $(0.0185)$ \\
\hline \multirow[t]{2}{*}{ Dedicated } & $0.0565^{* *}$ & $0.0572^{* *}$ & $0.0561^{* *}$ & $0.0577^{* *}$ & $0.0578^{* *}$ \\
\hline & $(0.0182)$ & $(0.0182)$ & $(0.0182)$ & $(0.0182)$ & $(0.0182)$ \\
\hline \multirow[t]{2}{*}{ Tills } & $-0.371^{* *}$ & $-0.367^{* *}$ & $-0.372^{* *}$ & $-0.372^{* *}$ & $-0.370^{* *}$ \\
\hline & $(0.0908)$ & $(0.0907)$ & $(0.0908)$ & $(0.0921)$ & $(0.0918)$ \\
\hline \multirow[t]{2}{*}{ TillsRoot } & $1.674^{* *}$ & $1.658^{* *}$ & $1.678^{* *}$ & $1.680^{* *}$ & $1.669^{* *}$ \\
\hline & $(0.287)$ & $(0.286)$ & $(0.287)$ & $(0.289)$ & $(0.289)$ \\
\hline \multirow[t]{2}{*}{ IndirectCompetition } & 0.000123 & $0.000159^{+}$ & 0.000124 & 0.000124 & $0.000160^{+}$ \\
\hline & $(0.0000924)$ & $(0.0000934)$ & $(0.0000925)$ & (0.0000928) & $(0.0000939)$ \\
\hline \multirow[t]{2}{*}{ PopK1km } & $0.000954^{* *}$ & $0.000921^{* *}$ & $0.000956^{* *}$ & $0.000988^{* *}$ & $0.000957^{* *}$ \\
\hline & $(0.000291)$ & $(0.000291)$ & $(0.000291)$ & $(0.000291)$ & $(0.000292)$ \\
\hline \multirow[t]{2}{*}{ PovRatio1km } & -0.0923 & -0.0874 & -0.0920 & -0.0890 & -0.0846 \\
\hline & $(0.0857)$ & $(0.0857)$ & $(0.0858)$ & $(0.0858)$ & $(0.0858)$ \\
\hline \multirow[t]{2}{*}{ Bank1km } & $0.00777^{* *}$ & $0.00758^{* *}$ & $0.00778^{* *}$ & $0.00765^{* *}$ & $0.00749^{* *}$ \\
\hline & $(0.00126)$ & $(0.00126)$ & $(0.00126)$ & $(0.00126)$ & $(0.00127)$ \\
\hline \multirow[t]{2}{*}{ Bus1km } & $-0.00614^{* *}$ & $-0.00645^{* *}$ & $-0.00619^{* *}$ & $-0.00603^{* *}$ & $-0.00638^{* *}$ \\
\hline & $(0.00137)$ & $(0.00137)$ & $(0.00138)$ & $(0.00138)$ & $(0.00138)$ \\
\hline \multirow[t]{2}{*}{ _cons } & $5.395^{* *}$ & $5.387^{* *}$ & $5.405^{* *}$ & $5.434^{* *}$ & $5.431^{* *}$ \\
\hline & $(1.338)$ & $(1.328)$ & $(1.342)$ & $(1.320)$ & $(1.317)$ \\
\hline$N$ & 3580 & 3580 & 3580 & 3580 & 3580 \\
\hline $\operatorname{adj} . R^{2}$ & 0.294 & 0.295 & 0.294 & 0.295 & 0.296 \\
\hline
\end{tabular}

Standard errors in parentheses

${ }^{+} p<0.10,{ }^{*} p<0.05,{ }^{* *} p<0.01$

Table A3 OLS regression results with robust standard errors in parentheses 


\begin{tabular}{|c|c|c|c|c|c|}
\hline & $(1)$ & $(2)$ & $(3)$ & $(4)$ & $(5)$ \\
\hline StockoutRatio (SOR) & $\begin{array}{c}-0.760^{* *} \\
(0.133)\end{array}$ & $\begin{array}{c}-0.470^{* *} \\
(0.167)\end{array}$ & $\begin{array}{c}-0.762^{* *} \\
(0.133)\end{array}$ & $\begin{array}{c}-0.752^{* *} \\
(0.133)\end{array}$ & $\begin{array}{c}-0.486^{* *} \\
(0.167)\end{array}$ \\
\hline SystemDownRatio & $\begin{array}{l}-0.0426 \\
(0.0829)\end{array}$ & $\begin{array}{l}-0.0445 \\
(0.0830)\end{array}$ & $\begin{array}{l}-0.0432 \\
(0.0829)\end{array}$ & $\begin{array}{l}-0.0483 \\
(0.0829)\end{array}$ & $\begin{array}{l}-0.0499 \\
(0.0830)\end{array}$ \\
\hline PricingTransparency (PT) & $\begin{array}{l}0.191^{* *} \\
(0.0324)\end{array}$ & $\begin{array}{c}0.192^{* *} \\
(0.0323)\end{array}$ & $\begin{array}{l}0.170^{* *} \\
(0.0405)\end{array}$ & $\begin{array}{l}0.193^{* *} \\
(0.0323)\end{array}$ & $\begin{array}{c}0.175^{* *} \\
(0.0401)\end{array}$ \\
\hline Expertise (E) & $\begin{array}{l}0.154^{* *} \\
(0.0217)\end{array}$ & $\begin{array}{l}0.152^{* *} \\
(0.0217)\end{array}$ & $\begin{array}{l}0.154^{* *} \\
(0.0217)\end{array}$ & $\begin{array}{c}0.106^{* *} \\
(0.0293)\end{array}$ & $\begin{array}{c}0.110^{* *} \\
(0.0293)\end{array}$ \\
\hline DirectCompetition & $\begin{array}{l}-0.000202^{* *} \\
(0.0000560)\end{array}$ & $\begin{array}{c}-0.0000309 \\
(0.0000780)\end{array}$ & $\begin{array}{l}-0.000373^{*} \\
(0.000180)\end{array}$ & $\begin{array}{c}-0.000491^{* *} \\
(0.000120)\end{array}$ & $\begin{array}{l}-0.000457^{*} \\
(0.000206)\end{array}$ \\
\hline SOR x DirectCompetition & & $\begin{array}{l}-0.00279^{* *} \\
(0.000836)\end{array}$ & & & $\begin{array}{l}-0.00259^{* *} \\
(0.000839)\end{array}$ \\
\hline PT x DirectCompetition & & & $\begin{array}{c}0.000182 \\
(0.000183)\end{array}$ & & $\begin{array}{c}0.000170 \\
(0.000176)\end{array}$ \\
\hline E x DirectCompetition & & & & $\begin{array}{l}0.000351^{* *} \\
(0.000125)\end{array}$ & $\begin{array}{l}0.000310^{*} \\
(0.000124)\end{array}$ \\
\hline Male & $\begin{array}{l}0.0831^{* *} \\
(0.0170)\end{array}$ & $\begin{array}{l}0.0832^{* *} \\
(0.0170)\end{array}$ & $\begin{array}{l}0.0829^{* *} \\
(0.0170)\end{array}$ & $\begin{array}{l}0.0836^{* *} \\
(0.0170)\end{array}$ & $\begin{array}{l}0.0834^{* *} \\
(0.0170)\end{array}$ \\
\hline CountryAge & $\begin{array}{c}-0.0757^{* *} \\
(0.0225)\end{array}$ & $\begin{array}{c}-0.0752^{* *} \\
(0.0223)\end{array}$ & $\begin{array}{c}-0.0756^{* *} \\
(0.0226)\end{array}$ & $\begin{array}{c}-0.0760^{* *} \\
(0.0223)\end{array}$ & $\begin{array}{c}-0.0755^{* *} \\
(0.0222)\end{array}$ \\
\hline NumUsersMM & $\begin{array}{c}0.431^{*} \\
(0.176)\end{array}$ & $\begin{array}{l}0.428^{*} \\
(0.175)\end{array}$ & $\begin{array}{l}0.431^{*} \\
(0.177)\end{array}$ & $\begin{array}{l}0.433^{*} \\
(0.174)\end{array}$ & $\begin{array}{l}0.429^{*} \\
(0.174)\end{array}$ \\
\hline Sunday & $\begin{array}{c}0.155^{* *} \\
(0.0173)\end{array}$ & $\begin{array}{c}0.155^{* *} \\
(0.0173)\end{array}$ & $\begin{array}{l}0.154^{* *} \\
(0.0173)\end{array}$ & $\begin{array}{c}0.155^{* *} \\
(0.0173)\end{array}$ & $\begin{array}{l}0.155^{* *} \\
(0.0173)\end{array}$ \\
\hline Dedicated & $\begin{array}{l}0.0708^{* *} \\
(0.0166)\end{array}$ & $\begin{array}{l}0.0712^{* *} \\
(0.0166)\end{array}$ & $\begin{array}{l}0.0706^{* *} \\
(0.0166)\end{array}$ & $\begin{array}{l}0.0719^{* *} \\
(0.0166)\end{array}$ & $\begin{array}{l}0.0719^{* *} \\
(0.0166)\end{array}$ \\
\hline Tills & $\begin{array}{l}-0.380^{* *} \\
(0.0794)\end{array}$ & $\begin{array}{l}-0.376^{* *} \\
(0.0793)\end{array}$ & $\begin{array}{l}-0.381^{* *} \\
(0.0794)\end{array}$ & $\begin{array}{l}-0.380^{* *} \\
(0.0805)\end{array}$ & $\begin{array}{l}-0.377^{* *} \\
(0.0803)\end{array}$ \\
\hline TillsRoot & $\begin{array}{l}1.716^{* *} \\
(0.251)\end{array}$ & $\begin{array}{l}1.698^{* *} \\
(0.250)\end{array}$ & $\begin{array}{l}1.721^{* *} \\
(0.251)\end{array}$ & $\begin{array}{l}1.718^{* *} \\
(0.253)\end{array}$ & $\begin{array}{l}1.705^{* *} \\
(0.253)\end{array}$ \\
\hline IndirectCompetition & $\begin{array}{c}0.000170^{*} \\
(0.0000828)\end{array}$ & $\begin{array}{c}0.000202^{*} \\
(0.0000833)\end{array}$ & $\begin{array}{c}0.000172^{*} \\
(0.0000830)\end{array}$ & $\begin{array}{c}0.000171^{*} \\
(0.0000835)\end{array}$ & $\begin{array}{c}0.000201^{*} \\
(0.0000841)\end{array}$ \\
\hline PopK1km & $\begin{array}{l}0.000780^{* *} \\
(0.000271)\end{array}$ & $\begin{array}{l}0.000765^{* *} \\
(0.000271)\end{array}$ & $\begin{array}{l}0.000787^{* *} \\
(0.000271)\end{array}$ & $\begin{array}{l}0.000830^{* *} \\
(0.000271)\end{array}$ & $\begin{array}{l}0.000818^{* *} \\
(0.000272)\end{array}$ \\
\hline PovRatio1km & $\begin{array}{l}-0.142^{+} \\
(0.0758)\end{array}$ & $\begin{array}{l}-0.138^{+} \\
(0.0758)\end{array}$ & $\begin{array}{l}-0.141^{+} \\
(0.0758)\end{array}$ & $\begin{array}{l}-0.136^{+} \\
(0.0758)\end{array}$ & $\begin{array}{l}-0.133^{+} \\
(0.0758)\end{array}$ \\
\hline Bank1km & $\begin{array}{l}0.00730^{* *} \\
(0.00113)\end{array}$ & $\begin{array}{l}0.00714^{* *} \\
(0.00113)\end{array}$ & $\begin{array}{c}0.00732^{* *} \\
(0.00113)\end{array}$ & $\begin{array}{c}0.00719^{* *} \\
(0.00113)\end{array}$ & $\begin{array}{c}0.00707^{* *} \\
(0.00113)\end{array}$ \\
\hline Bus1km & $\begin{array}{c}-0.00698^{* *} \\
(0.00124)\end{array}$ & $\begin{array}{c}-0.00726^{* *} \\
(0.00124)\end{array}$ & $\begin{array}{c}-0.00703^{* *} \\
(0.00124)\end{array}$ & $\begin{array}{c}-0.00687^{* *} \\
(0.00125)\end{array}$ & $\begin{array}{c}-0.00718^{* *} \\
(0.00125)\end{array}$ \\
\hline _cons & $\begin{array}{l}5.515^{* *} \\
(1.050)\end{array}$ & $\begin{array}{l}5.481^{* *} \\
(1.044)\end{array}$ & $\begin{array}{l}5.525^{* *} \\
(1.055)\end{array}$ & $\begin{array}{l}5.567^{* *} \\
(1.042) \\
\end{array}$ & $\begin{array}{l}5.538^{* *} \\
(1.041)\end{array}$ \\
\hline$N$ & 4406 & 4406 & 4406 & 4406 & 4406 \\
\hline $\operatorname{adj} \cdot R^{2}$ & 0.327 & 0.328 & 0.327 & 0.329 & 0.329 \\
\hline
\end{tabular}

Standard errors in parentheses

Table A4 OLS regression results, using multiple imputation for missing data, with robust standard errors in 